\title{
Article \\ Levels of Salt Reduction in Bread, Acceptability and Purchase Intention by Urban Mozambican Consumers
}

\author{
Neusa Jessen ${ }^{1,2,3}$, Albertino Damasceno ${ }^{1,2,3,4} \oplus$, Patrícia Padrão ${ }^{1,2,5}$ and Nuno Lunet ${ }^{1,2,4, *}$ \\ 1 EPIUnit-Instituto de Saúde Pública, Universidade do Porto, Rua das Taipas nº 135, 4050-600 Porto, Portugal; \\ neusa.jessen@gmail.com (N.J.); tino_7117@hotmail.com (A.D.); padraopatricia@gmail.com (P.P.) \\ 2 Laboratório Para a Investigação Integrativa e Translacional em Saúde Populacional (ITR), Rua das Taipas, \\ $\mathrm{n}^{\mathrm{o}} 135,4050-600$ Porto, Portugal \\ 3 Departamento de Medicina, Hospital Central de Maputo, Avenida Eduardo Mondlane 1653, \\ Maputo 1100, Mozambique \\ 4 Departamento de Ciências da Saúde Pública e Forenses e Educação Médica, Faculdade de Medicina da \\ Universidade do Porto, Alameda Prof. Hernâni Monteiro, 4200-319 Porto, Portugal \\ 5 Faculdade de Ciências da Nutrição e Alimentação, Universidade do Porto, Rua Dr. Roberto Frias, \\ 4200-465 Porto, Portugal \\ * Correspondence: nlunet@med.up.pt; Tel.: +351-22-551-3652
}

Citation: Jessen, N.; Damasceno, A.; Padrão, P.; Lunet, N. Levels of Salt Reduction in Bread, Acceptability and Purchase Intention by Urban Mozambican Consumers. Foods 2022, 11, 454. https://doi.org/10.3390/ foods11030454

Academic Editor:

Jean-Xavier Guinard

Received: 11 November 2021

Accepted: 26 January 2022

Published: 3 February 2022

Publisher's Note: MDPI stays neutral with regard to jurisdictional claims in published maps and institutional affiliations.

Copyright: (C) 2022 by the authors. Licensee MDPI, Basel, Switzerland. This article is an open access article distributed under the terms and conditions of the Creative Commons Attribution (CC BY) license (https:// creativecommons.org/licenses/by/ $4.0 /)$.

\begin{abstract}
Excess sodium ( $\mathrm{Na}$ ) consumption is implicated in several health problems, particularly hypertension, and bread is an important dietary source. We aimed to analyze perception of salt, acceptability, and purchase intention of low-salt and unsalted white bread by consumers in Mozambique. Sensory evaluation was performed using a triangular test $(\mathrm{N}=42)$ to perceive if differences in saltiness were detected when comparing low-salt and unsalted with salt-reduced white bread. Nine-point hedonic and five-point purchase intention scales were used to measure acceptability and purchase intention, respectively $(\mathrm{N}=120)$. Difference in saltiness was not detected when fresh white bread with $282 \mathrm{mg} \mathrm{Na} / 100 \mathrm{~g}$ vs. $231 \mathrm{mg} \mathrm{Na} / 100 \mathrm{~g}$ and $279 \mathrm{mg} \mathrm{Na} / 100 \mathrm{~g}$ vs. $123 \mathrm{mg} \mathrm{Na} / 100 \mathrm{~g}$ were compared. Difference in saltiness was not detected when comparing unsalted vs. $64 \mathrm{mg}$ $\mathrm{Na} / 100 \mathrm{~g}$, while differences were detected when unsalted vs. $105 \mathrm{mg} \mathrm{Na} / 100 \mathrm{~g}$ and unsalted vs. $277 \mathrm{mg} \mathrm{Na} / 100 \mathrm{~g}$ were compared. Overall acceptability and purchase intention were not affected by reductions of $\mathrm{Na}$ in bread. A reduction of up to more than $50 \%$ of $\mathrm{Na}$ was not perceived and a small level of Na was not distinguished from unsalted bread. Consumers were shown to accept and be willing to buy both unsalted and salt-reduced bread, suggesting that Na can be reduced from current levels.
\end{abstract}

Keywords: sodium; salt; bread; perception; acceptability; purchase intention; sensory evaluation; Mozambique

\section{Introduction}

Excessive dietary salt is an important preventable risk factor for several health problems [1-7]. The absolute global burden due to high Na intake increased significantly during the last three decades (from 1990 to 2019), with an estimated rise in the total number of attributable deaths and disability-adjusted life-years (DALYs) of around 0.57 million and 11.48 million, respectively [8].

High $\mathrm{Na}$ intake has been especially associated with cardiovascular morbidity and mortality [7,9-13], with a direct influence on high blood pressure and probably on stroke mortality [14-19].

The World Health Organization (WHO) recommends a maximum daily intake of $2000 \mathrm{mg}$ of $\mathrm{Na}$ (equivalent to $5000 \mathrm{mg}$ of salt) [20]. However, overall high intakes have been found in several populations [21], including in Africa, and particularly in urban settings [22,23]. In Mozambique, the mean 24-h urinary Na excretion, evaluated in a 
sample of Maputo dwellers, was found to be twice the recommended by the WHO [24]. Reducing salt intake at the population level has been shown to be a cost-effective and cost-saving intervention [25-27], and reformulation of processed foods is one of the three core pillars recommended by the WHO to promote such reduction [28]. Bread is a common target of food reformulation. This is not surprising given that it is frequently rich in salt and accessible, representing an important part of the daily diet of several populations [29], including the Mozambican [24,30].

In fact, in Mozambique, a study performed in 2012 evaluated the salt content of white bread available for purchase in the city of Maputo and found a mean Na level of $450.3 \mathrm{mg}$ $\mathrm{Na} / 100 \mathrm{~g}$ of white bread [31]. However, a high variability in salt content in white bread was observed between bakeries, which is in line with the lack of legislation or a formal recommendation for the amount of salt that is added during bread preparation. In a new evaluation performed in 2018, the mean Na content in white bread was lower by just over $10 \%$, and other varieties of bread were also available, including unsalted bread [32], showing that some consumers actually choose salt reduced bread.

Food choice is highly influenced by taste. Perception of salt taste depends on the activation of taste receptors and the subsequent production of electrical impulses that are sent to the brain. This process requires a certain concentration of $\mathrm{Na}$ (the recognition threshold) below which the electrical signal may not be enough to elicit saltiness. When $\mathrm{Na}$ is reduced from food, several flavor effects are affected and a wide range of complex taste interactions occur [33]. The stealth approach, consisting of a gradual reduction of salt in foods, modifies the salt taste experience of consumers over time until it goes unnoticeable. This strategy has shown promising results in the UK population, has the advantage of not depending on behavior change, and can allow for large Na reductions in foods [33]. In fact, previous studies have shown that taste adapts to lower salt concentrations in food [34] and, in experiences with salt reduced bread, consumers were not able to detect differences in saltiness, maintaining acceptability $[35,36]$. However, such evaluations are not available in Mozambique and setting-specific data are needed, given the recognized differences in dietary habits and taste preferences across populations. As such, we aimed to assess the levels of salt reduction in bread that urban Mozambican consumers could detect, as well as acceptability and purchase intention of bread with different salt contents.

\section{Material and Methods}

\subsection{Bread Production}

In July of 2018, a researcher observed the usual process of bread production in a local bakery and registered all ingredients, the weights, and the steps that were followed. Subsequently, taking into account that $1 \mathrm{~g}$ of salt contains $400 \mathrm{mg}$ of $\mathrm{Na}$, five batches of white bread were produced using the same recipe but changing the amount of salt added, in order to produce breads with different concentrations of $\mathrm{Na}$ (according to estimates for what was to be tested). The recipe consisted of: $1 \mathrm{~kg}$ of white bread flour (locally refined wheat flour, from the ${ }^{\circledR}$ MEREC industries SA [37]), $0.1 \%$ of additive ( $1 \mathrm{~g}$, ascorbic acid), $3 \%$ of bread yeast $(30 \mathrm{~g}), 70 \%$ water $(700 \mathrm{~g})$ and the desired amount of salt. All ingredients were carefully weighed using a precision automatic scale, the salt was dissolved in the water, and the dough was prepared by adding and mixing the ingredients with an automatic spiral dough mixer machine, as follows: first, the flour, the salted water, and the additive were mixed together for $30 \mathrm{~min}$, then the yeast was added and mixed for an additional $10 \mathrm{~min}$. The dough was divided in eight equal parts and left to rise for $45 \mathrm{~min}$ before baking. Once ready, each loaf of bread weighed around $220 \mathrm{~g}$. The bread loaves were let to cool down and, from each batch of eight breads, four were homogenized with crust and four without crust. A sample of each homogenized bread was collected, frozen and sent for $\mathrm{Na}$ analysis at the University of Porto, in Portugal. Results from such analysis were used for the production of breads for the testing sessions. 


\subsection{Preparation and Analysis of Bread for the Testing Sessions}

Bread for the tests was produced in the afternoon of the day before the testing session, in the same local bakery, following the same procedures of bread production. The amount of salt added to each type of bread produced for the testing sessions was based on the $\mathrm{Na}$ content in bread that was found in the laboratory analysis. Each batch was composed of 12 breads (with around $150 \mathrm{~g}$ each) with a specific salt concentration. Once baked, the bread was let to cool down, six breads were homogenized (three with crusts and three without crusts) and samples of $30 \mathrm{~g}$ were taken from each, packed, frozen, and sent for analysis at the University of Porto. The remaining six breads were cut and stored in labelled plastic boxes until the testing session.

The homogenized bread samples were defrosted at room temperature and two aliquots, of approximately $2 \mathrm{~g}$, were collected from each sample of bread and analyzed for $\mathrm{Na}$ content, using flame photometry (flame photometer model PFP7; JenWay ${ }^{\circledR}$, Dunmow, UK) according to a previously validated method [38]. Two readings were taken from each of the two aliquots and the mean of the results from the three samples (of the same type of bread, without crust) was used for data analysis. The Na concentrations that are presented throughout the manuscript correspond to the mean results obtained from the laboratory analysis of the samples without crust.

\subsection{Selection of Participants}

Participants were dwellers in the city of Maputo, the capital and most urbanized city of Mozambique, recruited among adult employees of the Central Hospital of Maputo. Convenience samples were selected, aiming for similar proportions of males and females, in the age-groups 18-44 years and $\geq 45$ years, and with a number of complete years of education, $<9$ and $\geq 9$ years, as described in Table 1. Pregnant women were not included. Most individuals participated in the evaluations conducted in more than one day.

Table 1. Tests performed and sociodemographic characteristics of participants.

\begin{tabular}{|c|c|c|c|c|c|c|c|}
\hline \multirow{3}{*}{$\begin{array}{c}\text { Test Applied } \\
\text { Experiment Performed } \\
\text { Day of experiment }\end{array}$} & \multicolumn{5}{|c|}{ Difference Testing * } & \multicolumn{2}{|c|}{ Acceptability Testing } \\
\hline & \multicolumn{2}{|c|}{ Salt Reduction } & \multicolumn{3}{|c|}{ Salt Increase } & \multirow{2}{*}{$\begin{array}{c}\begin{array}{c}\text { Different Salt } \\
\text { Leves (High) }\end{array} \\
\# 6\end{array}$} & \multirow{2}{*}{$\begin{array}{c}\begin{array}{c}\text { Different Salt } \\
\text { Leves (Low) }\end{array} \\
\# 7\end{array}$} \\
\hline & $\# 1$ & \# 2 & \#3 & $\# 4$ & \# 5 & & \\
\hline $\begin{array}{l}\text { Na concetrations tested } \\
(\mathrm{mg} \mathrm{Na} / 100 \mathrm{~g} \text { bread })\end{array}$ & $282 \rightarrow 231$ & $279 \rightarrow 123$ & $0 \rightarrow 64$ & $0 \rightarrow 105$ & $0 \rightarrow 277$ & 292 vs. 215 vs. 173 & 77 vs. 59 vs. 0 \\
\hline Participants (N) & 42 & 42 & 42 & 42 & 42 & 120 & 120 \\
\hline Female $(\%)$ & $50 \%$ & $50 \%$ & $52.4 \%$ & $50 \%$ & $50 \%$ & $55.8 \%$ & $53.3 \%$ \\
\hline Age, mean years (SD) & $46(11.2)$ & $45(12.3)$ & $46(11.3)$ & $45(12.1)$ & $46(11.4)$ & $41(10.6)$ & $43(11.0)$ \\
\hline Level of education $<9^{+}(\%)$ & $47.6 \%$ & $50 \%$ & $50 \%$ & $50 \%$ & $50 \%$ & $38.3 \%$ & $48.3 \%$ \\
\hline
\end{tabular}

SD, standard deviation; ${ }^{*}$ Triangular test; ${ }^{\dagger}$ Years of school completed.

Habits of bread consumption were also assessed in the beginning of the test. The proportion of participants who reported eating bread every day ranged from $85.7 \%$ to $90.8 \%$ across all sessions and the number of breads eaten per day ranged from half (around $75 \mathrm{~g}$ ) to four breads (around $600 \mathrm{~g}$ ), with just above $50 \%$ of participants consuming at least one bread per day (around $150 \mathrm{~g}$ ).

The present study was conducted in accordance with the Declaration of Helsinki Ethical Principles. Ethical approval was granted by the Ethics Committee of the Faculty of Medicine of University Eduardo Mondlane in Maputo (CIBIS-FM \& HCM/074/2018) and written informed consent was obtained from all participants. The scientific direction of the Central Hospital of Maputo consented to the participation of employees and for the study to be conducted within the Hospital premises. 


\subsection{Bread Testing Sessions}

This study comprised sensory evaluation [39] through difference testing, to assess differences in the levels of salt in bread that consumers could detect, and acceptability and purchase intention testing of bread with different salt contents. The former focused on the comparison of samples of fresh bread with Na levels at around $280 \mathrm{mg} / 100 \mathrm{~g}$ with samples with gradually lower concentrations ( $\approx 230 \mathrm{mg} / 100 \mathrm{~g}$ and $\approx 120 \mathrm{mg} / 100 \mathrm{~g})$, as well as on the comparison of samples of fresh bread with no added salt with samples with increasing Na concentrations ( $\approx 60 \mathrm{mg} / 100 \mathrm{~g}, \approx 100 \mathrm{mg} / 100 \mathrm{~g}, \approx 280 \mathrm{mg} / 100 \mathrm{~g})$. The latter focused on the evaluation of samples with different Na levels, namely $\approx 290 \mathrm{mg} / 100 \mathrm{~g}, 215 \mathrm{mg} / 100 \mathrm{~g}$, $\approx 170 \mathrm{mg} / 100 \mathrm{~g}, \approx 80 \mathrm{mg} / 100 \mathrm{~g}, \approx 60 \mathrm{mg} / 100 \mathrm{~g}$, and no added salt (Table 1).

For the testing sessions, samples were prepared by slicing the fresh loaf of bread, discarding the ends, cutting each slice in half and removing the crusts. Multiple threedigit codes were randomly selected and assigned to each sample by labelling individual white plates (Supplementary Figure S1). Therefore, different samples from the same bread received different codes and, as such, participants seated next to each other received samples with different codes.

Each participant received three samples of bread per session, that were presented simultaneously [40]. To prevent presentation bias, the order of presentation of the samples was randomized and balanced across participants.

Participants were given general information regarding the objectives of the study and instructed to taste the samples starting from the left, to drink some water between the samples to cleanse the palate, and then to mark their answer in the paper form that was provided.

\subsubsection{Difference Testing}

Difference testing was accomplished through the triangular test methodology [39,40], between September and October 2019. A total of 42 participants were involved in each of the five days of testing sessions as described in Table 1. The testing sessions took place once a week, during the morning (six sessions with seven persons in each, in a room of the Central Hospital of Maputo, organized with individual tables and chairs (Supplementary Figure S1).

Participants received three samples, two from the same bread and another from a bread with a different salt content; each sample was identified with a random three-digit code. Using the letters $\mathrm{A}$ and $\mathrm{B}$ to represent the order of presentation of the least and the more salted samples, respectively, the possibilities of presentation were: $\mathrm{ABB}, \mathrm{BAB}, \mathrm{BBA}$, $\mathrm{AAB}, \mathrm{ABA}, \mathrm{BAA}$. Participants were told that one of the samples that they were about to taste was different, either had more or less salt, were instructed to taste the three samples and then select the odd sample among them using the form provided (Supplementary Figure S1). This is a forced choice test and participants had to give an answer even if they were not sure of the difference.

\subsubsection{Acceptability and Purchase Intention Testing}

Acceptability and purchase intention testing were performed after the conclusion of difference testing, in December of 2019. A total of 120 participants were involved in each of the two days of testing sessions (six sessions with 10 participants in the morning and six sessions in the afternoon), which took place in the same week, two days apart (Table 1).

Assessors tasted three samples of bread with different salt concentrations; each sample was identified with a random three-digit code. Using the letters A, B and C to represent samples with different concentrations of $\mathrm{Na}$, the possibilities of presentation were: $\mathrm{ABC}$, $\mathrm{CAB}, \mathrm{BCA}, \mathrm{BAC}, \mathrm{ACB}, \mathrm{CBA}$. They were told that they were about to taste breads with different salt contents and instructed to taste the one at a time and to rate the first sample regarding acceptability and purchase intention by filling the forms provided.

Acceptability was evaluated using a Portuguese version of the nine-point hedonic scale [41], where: $9=$ 'like extremely', $8=$ 'like very much', $7={ }^{\prime}$ like moderately', $6=$ 'like 
slightly', 5 = 'neither like nor dislike', 4 = 'dislike slightly', 3 = 'dislike moderately', 2 = 'dislike very much'; and 1 = 'dislike extremely'.

Purchase intention was evaluated using a Portuguese version of a five-point scale, where: $5=$ 'definitely buy', $4=$ 'probably buy', $3=$ 'might or might not buy' $2=$ 'probably not buy'; and $1=$ 'definitely not buy'.

\subsection{Statistical Analysis}

For the difference test, a sample size of 42 was calculated, to be able to detect differences of at least $25 \%$ in Na content in relation to the probability of detecting the odd sample by chance (one third), for a confidence level of $95 \%$ and a power of $90 \%$. Binomial probability distribution was used, with a probability of success of one third, to calculate the upper critical value or the maximum number of correct identifications in the triangular test until statistical significance; this value was found to be 19. The Chi-squared test was used to compare the difference in the number of correct identifications according to demographic characteristics.

For the acceptability test, to estimate a difference between sample means of 0.8 on the nine-point hedonic scale ( $10 \%$ of the sensory scale), assuming a confidence level of $95 \%$, a power of $90 \%$, and a root mean square error divided by the scale length (RMSL) of 0.23 (averaged from other studies) with a standard deviation of 0.037 , a sample of 112 consumers was needed [42]. We assembled a sample of 120 participants.

Mean scores were calculated for acceptability and purchase intention of each sample, overall and according to socio-demographic variables. For acceptability and purchase intention testing, one-way ANOVA was used when variances were homogeneous, or the Welch test otherwise, to evaluate if there was a significant difference in mean scores across the bread types. Independent samples $t$-test was used to determine if the mean scores of acceptability and purchase intention were significantly different according to gender, age, or level of education.

Analyses were conducted using IBM ${ }^{\circledR}$ SPPSS $^{\circledR}$ statistics package, version 26, and, for all analyses, statistical significance was set at the 0.05 level.

\section{Results}

\subsection{Difference Testing}

Results from difference testing are depicted in Figure 1 . The odd sample was correctly identified by $15 / 42$ participants (35.7\%) when $282 \mathrm{mg} \mathrm{Na} / 100 \mathrm{~g}$ vs. $231 \mathrm{mg} \mathrm{Na} / 100 \mathrm{~g}$ were compared, and by $17 / 42$ participants (40.5\%) when comparing $279 \mathrm{mg} \mathrm{Na} / 100 \mathrm{~g}$ vs. $123 \mathrm{mg}$ $\mathrm{Na} / 100 \mathrm{~g}$. In both cases the proportion of correct answers was not significantly different from the $33.3 \%$ that are expected by chance in the triangular test. When comparing fresh bread samples with no added salt with samples with $64 \mathrm{mg} \mathrm{Na} / 100 \mathrm{~g}$, participants did not detect the difference between samples (15/42 correct answers, $35.7 \%)$. The odd sample was correctly identified by $20 / 42$ participants $(47.6 \%)$ when samples with no added salt vs. $105 \mathrm{mg} \mathrm{Na} / 100 \mathrm{~g}$ were compared, and by $22 / 42$ participants ( $52.4 \%$ ) when comparing samples with no added salt vs. $277 \mathrm{mg} \mathrm{Na} / 100 \mathrm{~g}$. No consistent statistically significant differences were observed between males and females, according to age $(<$ or $\geq 45$ years old) or level of education ( $<$ or $\geq 9$ years) (Table 2 ). 


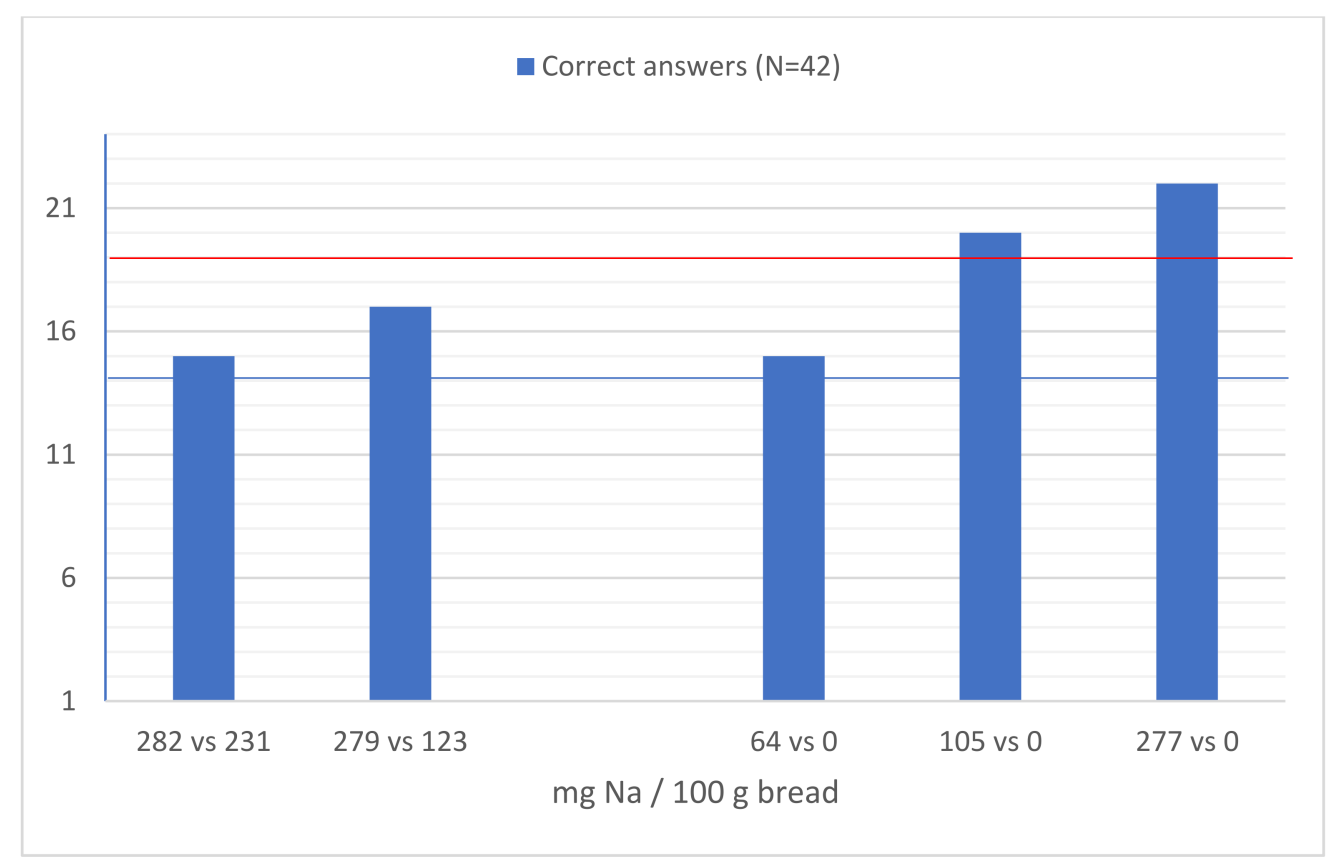

Figure 1. Results from difference testing; 14-number of correct answers by chance; 19-maximum number of correct answers until statistical significance.

Table 2. Comparison of correct answers in difference testing and scores of acceptability and purchase intention testing, according to demographic variables.

\begin{tabular}{|c|c|c|c|c|c|c|c|c|c|}
\hline \multirow[b]{2}{*}{ Test } & \multicolumn{2}{|c|}{ Gender } & \multirow[b]{2}{*}{$p$} & \multicolumn{2}{|c|}{ Age (Years Old) } & \multicolumn{4}{|c|}{ Level of Education * } \\
\hline & Female & Male & & $18-44$ & $\geq 45$ & $p$ & $<9$ & $\geq 9$ & $p$ \\
\hline \multicolumn{10}{|c|}{ Difference $^{\dagger}(\mathrm{n} / \mathrm{N})^{\ddagger}$} \\
\hline 282 vs. 231 & $9 / 21$ & $6 / 21$ & 0.334 & $8 / 21$ & $7 / 21$ & 0.747 & $5 / 20$ & $10 / 22$ & 0.167 \\
\hline 279 vs. 123 & $8 / 21$ & $9 / 21$ & 0.753 & $9 / 21$ & $8 / 21$ & 0.753 & $11 / 21$ & $6 / 21$ & 0.116 \\
\hline 105 vs. 0 & $12 / 21$ & $8 / 21$ & 0.217 & $14 / 21$ & $6 / 21$ & 0.013 & $7 / 21$ & $13 / 21$ & 0.064 \\
\hline 64 vs. 0 & $10 / 22$ & $5 / 20$ & 0.167 & $6 / 21$ & $9 / 21$ & 0.334 & $8 / 21$ & $7 / 21$ & 0.747 \\
\hline 277 vs. 0 & $10 / 21$ & $12 / 21$ & 0.537 & $10 / 21$ & $12 / 21$ & 0.537 & $11 / 21$ & $11 / 21$ & 1.000 \\
\hline \multicolumn{10}{|c|}{ Acceptability [Mean score (SD)] } \\
\hline 292 & $6.52(1.75)$ & $6.21(2.15)$ & 0.615 & $6.38(1.94)$ & $6.36(1.98)$ & 0.966 & $6.57(1.87)$ & $6.27(1.99)$ & 0.643 \\
\hline 215 & $6.16(1.70)$ & $6.00(1.77)$ & 0.778 & $6.29(1.51)$ & $5.67(2.10)$ & 0.299 & $5.63(1.93)$ & $6.42(1.50)$ & 0.153 \\
\hline 173 & $5.71(1.87)$ & $6.47(1.68)$ & 0.187 & $5.96(1.91)$ & $6.29(1.64)$ & 0.594 & $6.56(1.46)$ & $5.57(1.96)$ & 0.166 \\
\hline 77 & $6.00(1.61)$ & $5.47(2.29)$ & 0.403 & $5.60(2.09)$ & $5.90(1.86)$ & 0.634 & $5.65(2.01)$ & $5.85(1.95)$ & 0.751 \\
\hline 59 & $6.27(1.48)$ & $5.00(2.09)$ & 0.030 & $6.08(1.44)$ & $5.07(2.34)$ & 0.098 & $5.53(2.06)$ & $5.86(1.71)$ & 0.583 \\
\hline 0 & $5.71(2.28)$ & $5.79(2.39)$ & 0.919 & $5.75(2.36)$ & $5.75(2.29)$ & 1.000 & $5.84(2.41)$ & $5.67(2.27)$ & 0.814 \\
\hline \multicolumn{10}{|c|}{ Purchase intention [Mean score (SD)] } \\
\hline 292 & $4.09(0.89)$ & 3.89 (1.15) & 0.539 & $4.19(0.85)$ & $3.64(1.22)$ & 0.102 & $3.71(1.20)$ & $4.15(0.88)$ & 0.194 \\
\hline 215 & $3.50(1.41)$ & $4.07(1.16)$ & 0.202 & $3.64(1.34)$ & $3.91(1.38)$ & 0.583 & $3.87(1.25)$ & $3.63(1.41)$ & 0.589 \\
\hline 173 & 3.38 (1.49) & 3.95 (1.31) & 0.213 & $3.88(1.48)$ & $3.21(1.25)$ & 0.158 & $3.62(1.15)$ & $3.67(1.61)$ & 0.929 \\
\hline 77 & 3.95 (1.07) & $3.26(1.09)$ & 0.052 & $3.70(0.98)$ & 3.55 (1.28) & 0.679 & 3.55 (1.23) & 3.70 (1.03) & 0.679 \\
\hline 59 & $4.05(1.21)$ & $3.50(1.20)$ & 0.164 & 3.92 (1.19) & $3.60(1.30)$ & 0.430 & $3.68(1.42)$ & $3.90(1.04)$ & 0.576 \\
\hline 0 & $3.81(1.37)$ & $3.68(1.42)$ & 0.777 & $3.71(1.46)$ & $3.81(1.28)$ & 0.818 & $3.58(1.39)$ & $3.90(1.38)$ & 0.461 \\
\hline
\end{tabular}

SD, standard deviation; ${ }^{*}$ Years of school completed; ${ }^{+}$Triangular testing $(n=19$ is the maximum number of correct identifications until statistical significance); ${ }^{\ddagger}$ Number of correct answers/total.

\subsection{Acceptability and Purchase Intention Testing}

Results from acceptability and purchase intention testing are depicted in Figure 2. When comparing fresh bread samples with $292 \mathrm{mg} \mathrm{Na} / 100 \mathrm{~g}, 215 \mathrm{mg} \mathrm{Na} / 100 \mathrm{~g}$ and $173 \mathrm{mg}$ $\mathrm{Na} / 100 \mathrm{~g}$, the mean acceptability scores $(6.18,5.83$, and 6.00 , respectively; $p=0.334)$, and the mean purchase intention scores $(3.69,3.60$, and 3.77, respectively; $p=0.612)$ were not significantly different. When comparing fresh bread samples with no added salt, $59 \mathrm{mg} \mathrm{Na} / 100 \mathrm{~g}$ and $77 \mathrm{mg} \mathrm{Na} / 100 \mathrm{~g}$, the mean acceptability scores $(5.64,6.01$, and 5.87 , respectively; $p=0.339)$, and the mean purchase intention scores $(3.63,3.88$, and 3.81 , 
respectively; $p=0.312$ ) were not significantly different. No consistent statistically significant differences were observed between males and females, according to age $(<$ or $\geq 45$ years old) or level of education ( $<$ or $\geq 9$ years) (Table 2 ).

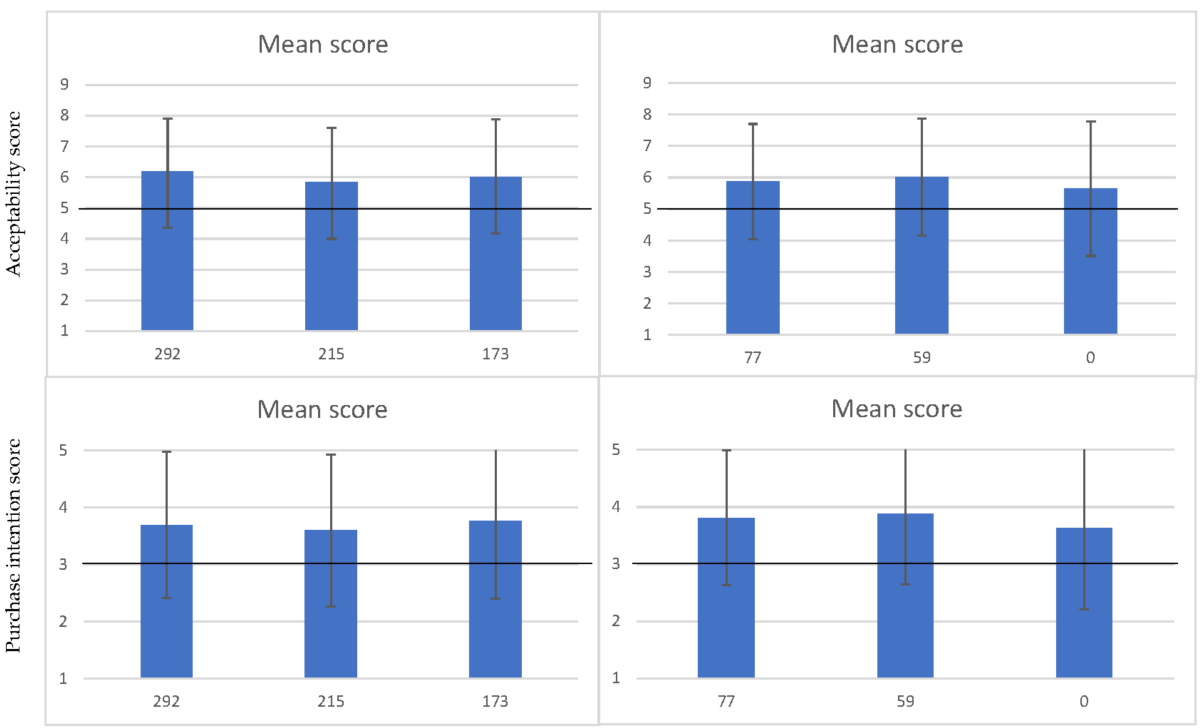

Figure 2. Mean scores for acceptability and purchase intention testing.

\section{Discussion}

In the present study, participants were not able to detect the difference between samples with $\approx 280 \mathrm{mg} \mathrm{Na} / 100 \mathrm{~g}$ fresh white bread compared with samples with less $18 \%$ and $56 \%$ of $\mathrm{Na}$. Moreover, participants could not detect the difference in saltiness when unsalted fresh white bread was compared with samples with $64 \mathrm{mg} \mathrm{Na} / 100 \mathrm{~g}$ fresh white bread. On the other hand, when comparing unsalted fresh white bread with $105 \mathrm{mg}$ $\mathrm{Na} / 100 \mathrm{~g}$ and with $277 \mathrm{mg} \mathrm{Na} / 100 \mathrm{~g}$, participants detected the difference, suggesting that in the lower extreme of $\mathrm{Na}$ in bread (increasing from unsalted), consumers detect saltiness more easily than in the upper extreme, where greater reductions could be made without being noticed. However, the acceptability and purchase intention did not decrease by reduction of salt or even by completely removing salt from bread.

Studies measuring consumer's acceptability of salt-reduced bread are scarce and most of the available studies were conducted in high-income countries [43]. Even so, in line with our findings, a previous study conducted in an indigenous Australian community, comparing fresh white bread with $400 \mathrm{mg} \mathrm{Na} / 100 \mathrm{~g}$ with reductions of $12.5 \%$ and $25 \%$ of $\mathrm{Na}$, found that consumers did not detect differences and liking of the bread did not change [36]. Furthermore, in Australia, in a randomized controlled study, cumulative reductions of $5 \%$ in salt content in bread were performed weekly for six consecutive weeks and acceptability was still similar to the control group [35]. Additionally, a gradual weekly reduction of up to $52 \%$ of $\mathrm{Na}$, from $498 \mathrm{mg} \mathrm{Na} / 100 \mathrm{~g}$ bread, was evaluated, showing that consumption of bread did not decrease and consumers did not compensate the lack of $\mathrm{Na}$ with saltier sandwich fillings [44].

The choice of food may be influenced by several factors, including individual taste perception. The possible influence of intrinsic (including genetics, gender, age, and ethnicity) and extrinsic factors (such as health conditions, medications, smoking, and weight) in the function of taste is not comprehensively described in the literature and while some studies found associations, others have not [45]. In their study, Puputti et al. [45] reported a reduced taste sensitivity among males (compared to females) and among older individuals. In a systematic review of studies on taste perception among young and older adults, the authors found that, although some studies corroborate the hypotheses of a decline in the sense of taste with ageing, the extent of such a decline was variable [46]. Perception 
of the intensity of saltiness has been related to socio-demographic characteristics, with some studies suggesting that elderly age and male gender are associated with reduced sensitivity to saltiness $[45,47]$. However, in the present study, the number of participants in each testing session was balanced with respect to gender and age groups and, in line with results from the study by McMahon et al. [36], we did not find consistent differences on saltiness perception and acceptability of the salt reduced bread according to sex and age. Additionally, higher serving temperature of the food seems to reduce sensitivity to saltiness among consumers used to eating food at lower temperatures [48], but, in our study, bread was served at room temperature in all sessions. The habit of smoking and male gender have also been associated to increased preference for salty foods [49], although others did not found association of smoking status with taste recognition or sensitivity [45]. Nevertheless, in the present study, among the participants of the acceptability test, the proportion of current smokers was less than 7\% (5/120 in the first day and 8/120 in the second day). Moreover, there were no statistically significant differences in perception of saltiness, acceptability, and purchase intention, according to level of education.

A modest reduction of salt intake, made over four or more weeks, was shown to significantly reduce blood pressure in both hypertensives and normotensives [19] and may reduce the risk of stroke and coronary heart disease in adults [9]. This is especially important in Mozambique, a low resource setting, with a very high prevalence of hypertension (39\% in 2014/2015) [50] but where a high proportion of hypertensives not on pharmacologic treatment were classified at low $(<10 \%)$ 10-year cardiovascular $(\mathrm{CV})$ risk [51]. Taking into account that the $\mathrm{CV}$ risk associated with high blood pressure begins at values as low as $115 \mathrm{mmHg}$ of systolic blood pressure and only half of hypertensive adults in Mozambique were found to be eligible for pharmacological treatment (according to WHO guidelines) [51], it would be important to start implementing potentially effective and cost-saving lifestyle interventions to prevent and control hypertension, such as salt intake reduction $[7,25,26]$. These should be urgently implemented in urban settings of the country, since hypertensives from urban areas have been shown to present higher total CV risk [51], and they should be progressively extended to rural areas. Several countries around the world are successfully implementing food reformulation to decrease salt content and reduce salt intake at the population level, and bread is the most commonly, and usually the first, targeted food product [52]. In fact, voluntary or mandatory targets for maximum $\mathrm{Na}$ content in bread have been defined in several countries [53-57], including in South Africa, where a regulation was set for a target of $<380 \mathrm{mg} \mathrm{Na} / 100 \mathrm{~g}$ [57]. Although such recommendations are not yet available in Mozambique, in a recent evaluation of trends in salt content of white bread produced in Maputo city from 2012 to 2018, we found that voluntary reduction is possible and actually occurred [32]. Nevertheless, with the current mean level of $\mathrm{Na}$ in white bread produced in Maputo of $419 \mathrm{mg} / 100 \mathrm{~g}$ [32], bread may be contributing with just over $20 \%$ for the maximum daily recommendation of $\mathrm{Na}$ intake for adults and even more for children [20]. The present study shows that such levels of $\mathrm{Na}$ can be further reduced. Additionally, establishing a target level would be important to guide producers and to reduce the large variability of the current $\mathrm{Na}$ levels observed across breads available in different bakeries. Voluntary reformulation may be the fastest and easiest starting point, but concerns regarding reduction of sales may arise among manufacturers and lead to resistance to change, especially due to the effects of $\mathrm{Na}$ reduction on palatability and on shelf life [58]. Nonetheless, it has been shown that although the complete removal of salt from bread leads to alterations on crumb structure starting on the fifth day after production, the quality of the bread is conserved even when very small levels of salt are added [58,59]. In fact, in the present study, the final bread quality was kept when salt was reduced or even completely removed, so acceptability and purchase intention of local consumers did not change. Even so, gradual reductions of $\mathrm{Na}$ in bread over time may be a better strategy to allow time for adaptation of taste sensors of the consumers. Furthermore, corroborating our results is the fact that unsalted bread is currently available for purchase in some bakeries 
of the city [32], attesting the technical feasibility and suggesting that other manufacturers may be convinced to widen their offer to include this variety of bread.

To the best of our knowledge, the present study is the first to assess perception of saltiness in bread, acceptability, and purchase intention of salt-reduced bread by Mozambicans, an African population [43,60]. Sound methodologies for sensorial analysis were selected, and a standardized experimental protocol was carefully elaborated and consistently followed during all the study, according to the principles of good practice that are recommended for each of the selected tests. As recommended for acceptability tests [40], a panel of bread consumers with no sensory training was selected and the local language was used for the test sessions. Even so, some limitations must be discussed. One of which is the fact that only adult consumers were included and, as such, the extrapolation of results to adolescents and children may not be possible. Moreover, the study was conducted with a sample of urban Maputo inhabitants and results may not directly apply to rural regions of the country or to other countries, where nutrition habits may vary. Additionally, since $\mathrm{Na}$ concentrations differ between crusts and the inner part of bread, to increase the homogeneity, only the inner part of the bread was used for testing and, as a consequence, the maximum tested concentration was $292 \mathrm{mg}$ of Na/100 g. Thus, it is not known if perception would be the same if consumers ate the bread with crusts. Nevertheless, in this kind of bread the crust is slim, and we do not expect that tasting the bread with crust would have a large impact on results. In addition, it would be interesting to evaluate the averages of the scales by attributes of each bread, but since we were using untrained consumers as assessors, we did not rate each attribute of the bread (such as appearance, color, texture and softness), just the overall liking.

The present study adds to previous research on this topic by providing information on perception of saltiness and acceptability of low-salt bread from a sample of a southern African population, from a country located in the east coast, with a tropical climate. Most people live in the coastline and there are several salt producers, including big, registered industries and small, unregistered producers. Salt is widely available and used for seasoning (during cooking and on already cooked food) and to preserve food. Structural and population-level interventions present greater potential for salt intake reduction by this population [61] and the present study contributes with important guiding information. Nevertheless, since reduction of salt in bread may change its physical characteristics and disrupt the sensory profile, it would be important to obtain reliable quantitative information, based in instrumental analysis, to reassure manufacturers about the safety and quality of the salt-reduced bread. As such, further research is needed to better understand the effects of salt reduction in perishability of bread produced locally, to analyze if local consumers would adopt saltier fillings to compensate the reduction of $\mathrm{Na}$ in bread, and to evaluate perception and acceptability of salt reduced bread by children and adolescents and among rural dwellers. As future perspectives, after the evidence raised by the present study, the capacity to perform instrumental analysis and to address technological properties of salt-reduced bread in local laboratories should be pursued. Apart from improving our understanding of the influences that reducing salt in bread have on the technological processes of breadmaking and on the final attributes of the bread produced, applying instrumental analysis may provide important information for bread producers and for future comparisons with findings from different populations.

\section{Conclusions}

This study shows that it is possible to reduce the current level of Na in bread produced in Mozambique, keeping acceptability and purchase intention. Local consumers were not able to detect reductions of up to more than $50 \%$ of Na concentration and acceptability and purchase intention did not change when salt was reduced or completely removed from bread. Even when consumers detected the difference in salt content between breads, acceptability and willingness to purchase did not change significantly. Findings from the present research can be used by programs of nutrition and prevention and control of 
Non-Communicable Diseases of the Ministry of Health of Mozambique to define recommendations and influence the production of low-salt bread, to define bread procurement standards for public institutions, and to improve the food environment in the urban centers of the country.

Supplementary Materials: The following supporting information can be downloaded at: https: / / www.mdpi.com/article/10.3390/foods11030454/s1, Figure S1: Images of the testing sessions.

Author Contributions: Conceptualization, N.J., A.D., P.P. and N.L.; methodology, N.J., A.D., P.P. and N.L.; formal analysis, N.J. and N.L.; investigation, N.J., N.L. and P.P.; resources, N.J. and A.D.; software, N.J. and N.L.; data curation, N.J.; validation, N.J., A.D., P.P. and N.L.; writing-original draft preparation, N.J.; writing-review and editing, A.D., P.P., N.L. and N.J.; visualization, N.J. and N.L.; supervision, A.D. and N.L.; project administration, N.J., A.D., P.P. and N.L.; funding acquisition, N.J. and A.D. All authors have read and agreed to the published version of the manuscript.

Funding: This study was funded by national funds from the Foundation for Science and TechnologyFCT (Portuguese Ministry of Science, Technology and Higher Education), under the Unidade de Investigação em Epidemiologia-Instituto de Saúde Pública da Universidade do Porto (EPIUnit; UIDB/04750/2020).

Institutional Review Board Statement: The present study was conducted in accordance with the Declaration of Helsinki, and approved by the Ethics Committee of the Faculty of Medicine of University Eduardo Mondlane in Maputo (CIBIS-FM \& HCM/074/2018).

Informed Consent Statement: Informed consent was obtained from all subjects involved in the study.

Data Availability Statement: Data is contained within the article.

Acknowledgments: The authors gratefully acknowledge the management and the workers of the bakery SINAC, for kindly offering the space and all the necessary conditions for preparation of the bread for the experiences.

Conflicts of Interest: The authors declare no conflict of interest.

\section{References}

1. Wang, X.-Q.; Terry, P.D.; Yan, H. Review of salt consumption and stomach cancer risk: Epidemiological and biological evidence. World J. Gastroenterol. 2009, 15, 2204-2213. [CrossRef] [PubMed]

2. Martini, L.A.; Cuppari, L.; Colugnati, F.A.; Sigulem, D.M.; Szejnfeld, V.L.; Schor, N.; Heilberg, I.P. High sodium chloride intake is associated with low bone density in calcium stone-forming patients. Clin. Nephrol. 2000, 54, 85-93. [PubMed]

3. Antonios, T.; MacGregor, G. Salt intake: Potential deleterious effects excluding blood pressure. J. Hum. Hypertens. 1995, 9, 511-515. [PubMed]

4. Ritz, E.; Koleganova, N.; Piecha, G. Role of sodium intake in the progression of chronic kidney disease. J. Ren. Nutr. 2009, 19, 61-62. [CrossRef] [PubMed]

5. D'Elia, L.; Rossi, G.; Ippolito, R.; Cappuccio, F.P.; Strazzullo, P. Habitual salt intake and risk of gastric cancer: A meta-analysis of prospective studies. Clin. Nutr. 2012, 31, 489-498. [CrossRef] [PubMed]

6. Faraco, G.; Hochrainer, K.; Segarra, S.G.; Schaeffer, S.; Santisteban, M.M.; Menon, A.; Jiang, H.; Holtzman, D.M.; Anrather, J.; Iadecola, C. Dietary salt promotes cognitive impairment through tau phosphorylation. Nature 2019, 574, 686-690. [CrossRef]

7. He, F.J.; Tan, M.; Ma, Y.; MacGregor, G.A. Salt Reduction to Prevent Hypertension and Cardiovascular Disease: JACC State-of-theArt Review. J. Am. Coll. Cardiol. 2020, 75, 632-647. [CrossRef] [PubMed]

8. Chen, X.; Du, J.; Wu, X.; Cao, W.; Sun, S. Global burden attributable to high sodium intake from 1990 to 2019 . Nutr. Metab. Cardiovasc. Dis. 2021, 31, 3314-3321. [CrossRef]

9. Poggio, R.; Gutierrez, L.; Matta, M.G.; Elorriaga, N.; Irazola, V.; Rubinstein, A. Daily sodium consumption and CVD mortality in the general population: Systematic review and meta-analysis of prospective studies. Public Health Nutr. 2015, 18, 695-704. [CrossRef] [PubMed]

10. Aaron, K.J.; Sanders, P.W. Role of dietary salt and potassium intake in cardiovascular health and disease: A review of the evidence. Mayo Clin. Proc. 2013, 88, 987-995. [CrossRef] [PubMed]

11. Cook, N.R.; Appel, L.J.; Whelton, P.K. Lower levels of sodium intake and reduced cardiovascular risk. Circulation 2014, 129, 981-989. [CrossRef]

12. Mozaffarian, D.; Fahimi, S.; Singh, G.M.; Micha, R.; Khatibzadeh, S.; Engell, R.E.; Lim, S.; Danaei, G.; Ezzati, M.; Powles, J. Global Sodium Consumption and Death from Cardiovascular Causes. N. Engl. J. Med. 2014, 371, 624-634. [CrossRef] [PubMed] 
13. Wang, Y.-J.; Yeh, T.-L.; Shih, M.-C.; Tu, Y.-K.; Chien, K.-L. Dietary Sodium Intake and Risk of Cardiovascular Disease: A Systematic Review and Dose-Response Meta-Analysis. Nutrients 2020, 12, 2934. [CrossRef] [PubMed]

14. Elliott, P.; Stamler, J.; Nichols, R.; Dyer, A.R.; Stamler, R.; Kesteloot, H.; Marmot, M. Intersalt revisited: Further analyses of 24 hour sodium excretion and blood pressure within and across populations. Intersalt Cooperative Research Group. BMJ 1996, 312, 1249-1253. [CrossRef]

15. Forte, J.G.; Miguel, J.M.; Miguel, M.J.; de Padua, F.; Rose, G. Salt and blood pressure: A community trial. J. Hum. Hypertens. 1989, 3, 179-184. [PubMed]

16. Nagata, C.; Takatsuka, N.; Shimizu, N.; Shimizu, H. Sodium intake and risk of death from stroke in Japanese men and women Stroke 2004, 35, 1543-1547. [CrossRef]

17. Xie, J.X.; Sasaki, S.; Joossens, J.V.; Kesteloot, H. The relationship between urinary cations obtained from the INTERSALT study and cerebrovascular mortality. J. Hum. Hypertens. 1992, 6, 17-21. [PubMed]

18. Stamler, J.; Rose, G.; Stamler, R.; Elliott, P.; Dyer, A.; Marmot, M. INTERSALT study findings. Public health and medical care implications. Hypertension 1989, 14, 570-577. [CrossRef] [PubMed]

19. He, F.J.; Li, J.; MacGregor, G.A. Effect of longer term modest salt reduction on blood pressure: Cochrane systematic review and meta-analysis of randomised trials. BMJ 2013, 346, f1325. [CrossRef]

20. World Health Organization. Guideline: Sodium Intake for Adults and Children; WHO: Geneva, Switzerland, 2012.

21. Brown, I.; Tzoulaki, I.; Candeias, V.; Elliott, P. Salt intakes around the world: Implications for public health. Int. J. Epidemiol. 2009, 38, 791-813. [CrossRef] [PubMed]

22. Oyebode, O.; Oti, S.; Chen, Y.-F.; Lilford, R.J. Salt intakes in sub-Saharan Africa: A systematic review and meta-regression. Popul. Health Metr. 2016, 14, 1. [CrossRef] [PubMed]

23. Mizehoun-Adissoda, C.; Houinato, D.; Houehanou, C.; Chianea, T.; Dalmay, F.; Bigot, A.; Aboyans, V.; Preux, P.M.; Bovet, P.; Desport, J.C. Dietary sodium and potassium intakes: Data from urban and rural areas. Nutrition 2017, 33, 35-41. [CrossRef] [PubMed]

24. Queiroz, A.; Damasceno, A.; Jessen, N.; Novela, C.; Moreira, P.; Lunet, N.; Padrao, P. Urinary Sodium and Potassium Excretion and Dietary Sources of Sodium in Maputo, Mozambique. Nutrients 2017, 9, 830. [CrossRef] [PubMed]

25. Cobiac, L.J.; Vos, T.; Veerman, J.L. Cost-effectiveness of interventions to reduce dietary salt intake. Heart 2010, 96, 1920-1925. [CrossRef] [PubMed]

26. Smith-Spangler, C.M.; Juusola, J.L.; Enns, E.A.; Owens, D.K.; Garber, A.M. Population strategies to decrease sodium intake and the burden of cardiovascular disease: A cost-effectiveness analysis. Ann. Intern. Med. 2010, 152, 481-487. [CrossRef] [PubMed]

27. Bibbins-Domingo, K.; Chertow, G.M.; Coxson, P.G.; Moran, A.; Lightwood, J.M.; Pletcher, M.J.; Goldman, L. Projected Effect of Dietary Salt Reductions on Future Cardiovascular Disease. N. Engl. J. Med. 2010, 362, 590-599. [CrossRef]

28. World Health Organization (WHO). Reducing Salt Intake in Populations: Report of a WHO Forum and Technical Meeting, 5-7 October 2006, Paris, France. Available online: https://www.who.int/dietphysicalactivity/reducingsalt/en/index3.html (accessed on 4 January 2022).

29. Joossens, J.V.; Sasaki, S.; Kesteloot, H. Bread as a source of salt: An international comparison. J. Am. Coll. Nutr. 1994, 13, 179-183. [CrossRef]

30. Ministry of Planning and Development National Directorate of Studies and Policy Analysis. Poverty and Wellbeing in Mozambique: Third National Poverty Assessment. 2010. Available online: https://www.preventionweb.net/files/16411_ thirdnationalpovertyassessment.pdf (accessed on 10 December 2021).

31. Silva, V.; Padrao, P.; Novela, C.; Damasceno, A.; Pinho, O.; Moreira, P.; Lunet, N. Sodium content of bread from bakeries and traditional markets in Maputo, Mozambique. Public Health Nutr. 2015, 18, 610-614. [CrossRef]

32. Jessen, N.; Padrão, P.; Pinho, O.; Novela, C.; Moreira, P.; Damasceno, A.; Lunet, N. Sodium content of bread from bakeries in Maputo, Mozambique: Trends between 2012 and 2018. Public Health Nutr. 2020, 23, 1098-1102. [CrossRef]

33. Liem, D.G.; Miremadi, F.; Keast, R.S.J. Reducing sodium in foods: The effect on flavor. Nutrients 2011, 3, 694-711. [CrossRef]

34. Blais, C.A.; Pangborn, R.M.; Borhani, N.O.; Ferrell, M.F.; Prineas, R.J.; Laing, B. Effect of dietary sodium restriction on taste responses to sodium chloride: A longitudinal study. Am. J. Clin. Nutr. 1986, 44, 232-243. [CrossRef] [PubMed]

35. Girgis, S.; Neal, B.; Prescott, J.; Prendergast, J.; Dumbrell, S.; Turner, C.; Woodward, M. A one-quarter reduction in the salt content of bread can be made without detection. Eur. J. Clin. Nutr. 2003, 57, 616-620. [CrossRef] [PubMed]

36. McMahon, E.; Clarke, R.; Jaenke, R.; Brimblecombe, J. Detection of $12.5 \%$ and $25 \%$ Salt Reduction in Bread in a Remote Indigenous Australian Community. Nutrients 2016, 8, 169. [CrossRef] [PubMed]

37. MEREC Industries. Farinha de Trigo. Available online: https://www.merecindustries.com/pt/products/flours/wheat-flour/ farinha/ (accessed on 25 December 2021).

38. Vieira, E.; Soares, M.E.; Ferreira, I.M.; Pinho, O. Validation of a Fast Sample Preparation Procedure for Quantification of Sodium in Bread by Flame Photometry. Food Anal. Methods 2012, 5, 430-434. [CrossRef]

39. Harry, T. Lawless and Hildegarde Heymann, Sensory Evaluation of Food. Principles and Practices, 2nd ed.; Springer: Berlin/Heidelberg, Germany, 2010.

40. Carpenter, R.P.; Lyon, D.H.; Hasdell, T.A. Guidelines for Sensory Analysis in Food Product Development and Quality Control; Aspen Publishers: Gaithersburg, MD, USA, 2000.

41. Lim, J. Hedonic scaling: A review of methods and theory. Food Qual. Prefer. 2011, 22, 733-747. [CrossRef] 
42. Hough, G.; Wakeling, I.; Mucci, A.; Chambers, E.; Gallardo, I.M.; Alves, L.R. Number of consumers necessary for sensory acceptability tests. Food Qual. Prefer. 2006, 17, 522-526. [CrossRef]

43. Jaenke, R.; Barzi, F.; McMahon, E.; Webster, J.; Brimblecombe, J. Consumer acceptance of reformulated food products: A systematic review and meta-analysis of salt-reduced foods. Crit. Rev. Food Sci. Nutr. 2017, 57, 3357-3372. [CrossRef] [PubMed]

44. Bolhuis, D.P.; Temme, E.H.M.; Koeman, F.T.; Noort, M.W.J.; Kremer, S.; Janssen, A.M. A Salt Reduction of 50\% in Bread Does Not Decrease Bread Consumption or Increase Sodium Intake by the Choice of Sandwich Fillings. J. Nutr. 2011, 141, $2249-2255$. [CrossRef] [PubMed]

45. Puputti, S.; Aisala, H.; Hoppu, U.; Sandell, M. Factors explaining individual differences in taste sensitivity and taste modality recognition among Finnish adults. J. Sens. Stud. 2019, 34, e12506. [CrossRef]

46. Methven, L.; Allen, V.J.; Withers, C.A.; Gosney, M.A. Ageing and taste. Proc. Nutr. Soc. 2012, 71, 556-565. [CrossRef]

47. Mojet, J.; Heidema, J.; Christ-Hazelhof, E. Taste perception with age: Generic or specific losses in supra-threshold intensities of five taste qualities? Chem. Senses 2003, 28, 397-413. [CrossRef] [PubMed]

48. Kim, J.-W.; Samant, S.S.; Seo, Y.; Seo, H.-S. Variation in saltiness perception of soup with respect to soup serving temperature and consumer dietary habits. Appetite 2015, 84, 73-78. [CrossRef]

49. Lampuré, A.; Schlich, P.; Deglaire, A.; Castetbon, K.; Péneau, S.; Hercberg, S.; Méjean, C. Sociodemographic, Psychological, and Lifestyle Characteristics Are Associated with a Liking for Salty and Sweet Tastes in French Adults. J. Nutr. 2015, 145, 587-594. [CrossRef] [PubMed]

50. Jessen, N.; Damasceno, A.; Silva-Matos, C.; Tuzine, E.; Madede, T.; Mahoque, R.; Padrao, P.; Mbofana, F.; Polonia, J.; Lunet, N. Hypertension in Mozambique: Trends between 2005 and 2015. J. Hypertens. 2018, 36, 779-784. [CrossRef] [PubMed]

51. Damasceno, A.; Padrao, P.; Silva-Matos, C.; Prista, A.; Azevedo, A.; Lunet, N. Cardiovascular risk in Mozambique: Who should be treated for hypertension? J. Hypertens. 2013, 31, 2348-2355. [CrossRef] [PubMed]

52. Trieu, K.; Neal, B.; Hawkes, C.; Dunford, E.; Campbell, N.; Rodriguez-Fernandez, R.; Legetic, B.; McLaren, L.; Barberio, A.; Webster, J. Salt Reduction Initiatives around the World-A Systematic Review of Progress towards the Global Target. PLoS ONE 2015, 10, e0130247. [CrossRef]

53. Dunford, E.; Eyles, H.; Mhurchu, C.; Webster, J.; Neal, B. Changes in the sodium content of bread in Australia and New Zealand between 2007 and 2010: Implications for policy. Med. J. Aust. 2011, 195, 346-349. [CrossRef] [PubMed]

54. Portuguese Government. Lei n. ${ }^{\circ}$ 75/2009 de 12 de Agosto. Normas com Vista à Redução do Teor de Sal No Pão Bem Como Informação Na Rotulagem de Alimentos Embalados Destinados ao Consumo Humano [Standards to Reduce the Salt Content in Bread as Well as Information on the Labeling of Packaged Foods Intended for Human Consumption]. Available online: https:/ / dre.pt/dre/legislacao-consolidada/lei/2009-155873797 (accessed on 26 January 2022).

55. Labarthe, D.R. Sodium Reduction: Facts and Fiction; Division for Heart Disease and Stroke Prevention. National Center for Chronic Disease Prevention and Health Promotion. Centers for Disease Control and Prevention. 2011. Available online: https:/ / www.cdc.gov/grand-rounds/pp/2011/20110421-presentation-sodium-reduction.pdf (accessed on 10 December 2021).

56. Wyness, L.A.; Butriss, J.L.; Stanner, S.A. Reducing the population's sodium intake: The UK Food Standards Agency's salt reduction programme. Public Health Nutr. 2012, 15, 254-261. [CrossRef] [PubMed]

57. South Africa Government, Department of Health. Regulations Relating to the Reduction of Sodium in Certain Foodstuffs and Related Matters. Available online: https://www.gov.za/sites/default/files/gcis_document/201409/36274rg9934gon214.pdf (accessed on 10 January 2022).

58. Belz, M.C.E.; Ryan, L.A.M.; Arendt, E.K. The Impact of Salt Reduction in Bread: A Review. Crit. Rev. Food Sci. Nutr. 2012, 52, 514-524. [CrossRef]

59. Lynch, E.J.; Dal Bello, F.; Sheehan, E.M.; Cashman, K.D.; Arendt, E.K. Fundamental studies on the reduction of salt on dough and bread characteristics. Food Res. Int. 2009, 42, 885-891. [CrossRef]

60. Muthuri, S.K.; Oti, S.O.; Lilford, R.J.; Oyebode, O. Salt Reduction Interventions in Sub-Saharan Africa: A Systematic Review. PLoS ONE 2016, 11, e0149680. [CrossRef] [PubMed]

61. Hyseni, L.; Elliot-Green, A.; Lloyd-Williams, F.; Kypridemos, C.; O’Flaherty, M.; McGill, R.; Orton, L.; Bromley, H.; Cappuccio, F.P.; Capewell, S. Systematic review of dietary salt reduction policies: Evidence for an effectiveness hierarchy? PLoS ONE 2017, 12, e0177535. [CrossRef] [PubMed] 